\title{
The importance of non-carbonate mineral weathering as a soil formation mechanism within a karst weathering profile in the SPECTRA Critical Zone Observatory, Guizhou Province, China
}

\author{
Oliver W. Moore ${ }^{1} \cdot$ Heather L. Buss ${ }^{1}$ (D) Sophie M. Green ${ }^{2}$ Man Liu $^{3}$ • \\ Zhaoliang Song ${ }^{4}$
}

Received: 30 March 2017/Revised: 26 May 2017/ Accepted: 22 August 2017/Published online: 4 September 2017

(c) The Author(s) 2017. This article is an open access publication

\begin{abstract}
Soil degradation, including rocky desertification, of the karst regions in China is severe. Karst landscapes are especially sensitive to soil degradation as carbonate rocks are nutrient-poor and easily eroded. Understanding the balance between soil formation and soil erosion is critical for long-term soil sustainability, yet little is known about the initial soil forming processes on karst terrain. Herein we examine the initial weathering processes of several types of carbonate bedrock containing varying amounts of non-carbonate minerals in the SPECTRA Critical Zone Observatory, Guizhou Province, Southwest China. We compared the weathering mechanisms of the bedrock to the mass transfer of mineral nutrients in a soil profile developed on these rocks and found that soil formation and nutrient contents are strongly dependent upon the weathering of interbedded layers of more silicate-rich bedrock (marls). Atmospheric inputs from dust were also detected.
\end{abstract}

11th International Symposium on Geochemistry of the Earth's Surface.

Heather L. Buss

h.buss@bristol.ac.uk

1 School of Earth Sciences, University of Bristol, Bristol BS8 1RJ, UK

2 Geography, College of Life and Environmental Sciences, University of Exeter, Exeter EX4 4RJ, UK

3 School of Water Resources and Environment, China University of Geosciences (Beijing), Beijing 100083, People's Republic of China

4 Institute of the Surface-Earth System Science Research, Tianjin University, Tianjin 300072, People's Republic of China
Keywords Critical zone - Chemical weathering - Karst . Desertification · Guizhou Province

\section{Introduction}

Carbonate rocks are widely distributed across China, covering a total area of $\sim 3,430,000 \mathrm{~km}^{2}$ with the exposed area of the carbonate making up $\sim 13 \%$ of China's territory (Chinese Academy of Sciences 1979; Wang et al. 2014). The soils that form atop carbonate bedrock tend to be thin and highly susceptible to degradation, especially through subsurface erosion in the case of karst terrain. In the absence of significant aeolian input, formation of soils on carbonate bedrock is dependent on non-carbonate mineral "impurities" [i.e. silicate and metal (hydr)oxide minerals] because $(\mathrm{Ca}, \mathrm{Mg}) \mathrm{CO}_{3}$ dissolves completely during chemical weathering, leaving behind no residual mineral matrix to support soils. In a study of carbonate and non-carbonate rocks and associated soils in Guizhou Province, Southwest China, Chen and Bi (2011) found that non-carbonate rocks and soils have three times the trace element content of the carbonate rocks and soils and that higher value crops are grown in the non-carbonate regions.

Karst landscapes occupy $61.9 \%$ of the $30,240 \mathrm{~km}^{2}$ of Guizhou Province (Chen and Bi 2011) and 25.2\% of the province is affected by rocky desertification (Wang et al. 2014), creating serious economic and ecological problems (Huang and Cai 2007). Soil loss is the primary cause of karst rocky desertification (e.g. Wang 2003; Wang et al. 2014). The preferential loss of the most biologically active surface soil may significantly impact soil fertility, even in fertilized agricultural systems. The long-term sustainability of soils on a landscape is dependent on a balance between soil formation via weathering or deposition and soil loss 
via erosion. Despite this, the initial soil forming mechanisms in karst landscapes are poorly understood. Here we examine the chemical weathering mechanisms of bedrock in a karst watershed in Guizhou Province and the loss and gain of nutrient elements in the soil to determine the controls on soil formation and nutrient production in this sensitive environment.

\section{Methods}

\subsection{Field site and sampling}

The SPECTRA Critical Zone observatory (SCZO) is located within Puding County, Guizhou, Southwest China. The area has a humid sub-tropical climate, with a mean annual air temperature of $15.1{ }^{\circ} \mathrm{C}$ (Wang et al. 2014). Rainfall is monsoonal with a mean annual precipitation of $1378 \mathrm{~mm}$. Within Puding County there is approximately $863.7 \mathrm{~km}^{2}$ of exposed carbonate rocks, accounting for $79.2 \%$ of the county's total area. The rocks are mostly dolomite, limestone and contain some argillaceous minerals of Triassic and Permian age (Wang et al. 2014). Sampling was conducted in June 2016 in the Chenqi catchment in an abandoned pear orchard $\left(105^{\circ} 46^{\prime} 17^{\prime \prime} \mathrm{E}, 26^{\circ} 15^{\prime} 48^{\prime \prime} \mathrm{N}\right.$ WGS84 datum). A soil pit was dug to $70 \mathrm{~cm}$, where bedrock was reached, and bulk soil samples were collected from each horizon. Due to a lack of accessibility to the different lithologies at the bottom of the soil pit, rock samples were taken from a nearby outcrop from each of three visibly different beds, including limestone and two marls (carbonate-rich mudstone, one with a shale-like, platy cleavage) both fresh and weathered (Fig. 1). The outcrop lies just below the pit, stratigraphically.

\subsection{Laboratory analyses}

Polished $30 \mu \mathrm{m}$ thick petrographic thin sections were made of each bedrock lithology, with the samples only exposed to an anhydrous cooling fluid during preparation. A Hitachi S-3500N scanning electron microscope (SEM) and a Thermo Scientific $10 \mathrm{~mm}^{2}$ Silicon Drift Detector were used to couple backscattered electron (BSE) imaging with $1024 \times 1024$ pixel resolution elemental maps, measuring $2.8 \times 2.1 \mathrm{~mm}$. Elemental maps were produced at $20 \mathrm{kV}$, rastering the electron beam whilst the SDD records X-ray counts at different excitation energies corresponding to different elements. The elemental X-ray maps were produced with 40 frames per map (frame time $=100 \mathrm{~s}$ ). To determine mineral modal abundances, phase analysis was conducted on the X-ray maps using the Noran System Seven V3.2 software, by grouping together pixels of the scan area that display similar X-ray spectra (i.e., are chemically similar). Following lithium metaborate fusion, bulk rock samples were analyzed by inductively coupled plasma-optical emission spectrometry (ICP-OES) for solidstate elemental concentrations to support the results of the $\mathrm{X}$-ray maps. Both the X-ray and ICP-OES results were normalized to exclude $\mathrm{CO}_{3}$.

The solid-state elemental concentrations of bulk soils were also measured by ICP-OES. Mass transfer within the soil was determined by normalizing the measured solidstate concentrations of mobile elements to an assumed immobile element. The net mass loss or gain of the mobile component, relative to the parent material can then be determined by calculating the mass transfer coefficient, tau (Anderson et al. 2002):

$\tau_{i, j}=\left(\frac{C_{j, w} C_{i, p}}{C_{j, p} C_{i, w}}\right)-1$

where $(\tau)=$ mass transfer coefficient, tau; $i=$ immobile component; $\mathrm{j}=$ mobile component; $\mathrm{C}=$ mass fraction, $\mathrm{p}=$ parent material and $\mathrm{w}=$ weathered material. When $\tau_{i, j}=0$, no mobilization of $\mathrm{j}$ has occurred relative to the parent composition. When $\tau_{\mathrm{i}, \mathrm{j}}=-1$, component $\mathrm{j}$ has been completely lost and when $\tau_{i, j}>0$, component $j$ has been gained relative to the parent. Therefore, tau can be used to track the progress of weathering through a critical zone profile. Here we use the deepest sample in the soil pit as the parent material and assume that $\mathrm{Ti}$ is immobile (e.g. White et al. 1998).

\section{Results and discussion}

\subsection{Bedrock composition}

The limestone bedrock is composed primarily of calcite with some dolomite and minor quartz (Table 1). The unweathered Marl A bed contains $~ 75$ vol\% calcite, with significant proportions of $\mathrm{K}$-rich and $\mathrm{Fe}$-rich glauconites (Table 1). Marl A also contains minor sphene and apatite. The Marl B bed contains the lowest proportion of calcite ( $\sim 67 \%)$ of all the beds at the outcrop and also contains $\mathrm{K}$-rich and Fe-rich glauconite. Both marls show relative increases of quartz with weathering, suggesting it is conserved, and less of both glauconites (Table 1). Using the mineral volumes (Table 1) and mineral densities (Deer et al. 2013), we calculated bulk densities for the limestone, Marl A and Marl B beds of 2.71, 2.70 and $2.61 \mathrm{~g} \cdot \mathrm{cm}^{-3}$, respectively.

Bedrock elemental compositions are comparable as determined by both X-ray elemental mapping and ICPOES indicating that $\mathrm{Ca}$ is dominant in all of the rock 
Fig. 1 a Photograph of outcrop where bedrock was sampled with different lithologic units delineated. b Schematic of the outcrop sampled and bed thicknesses. Marl A was yellowish with a grey/white center; Weathered Marl A was $17 \mathrm{~cm}$ of rock and $3 \mathrm{~cm}$ of clay; Marl B and Weathered Marl B are below the schematic and display a platy cleavage
Table 1 Bedrock mineral compositions (vol\%)
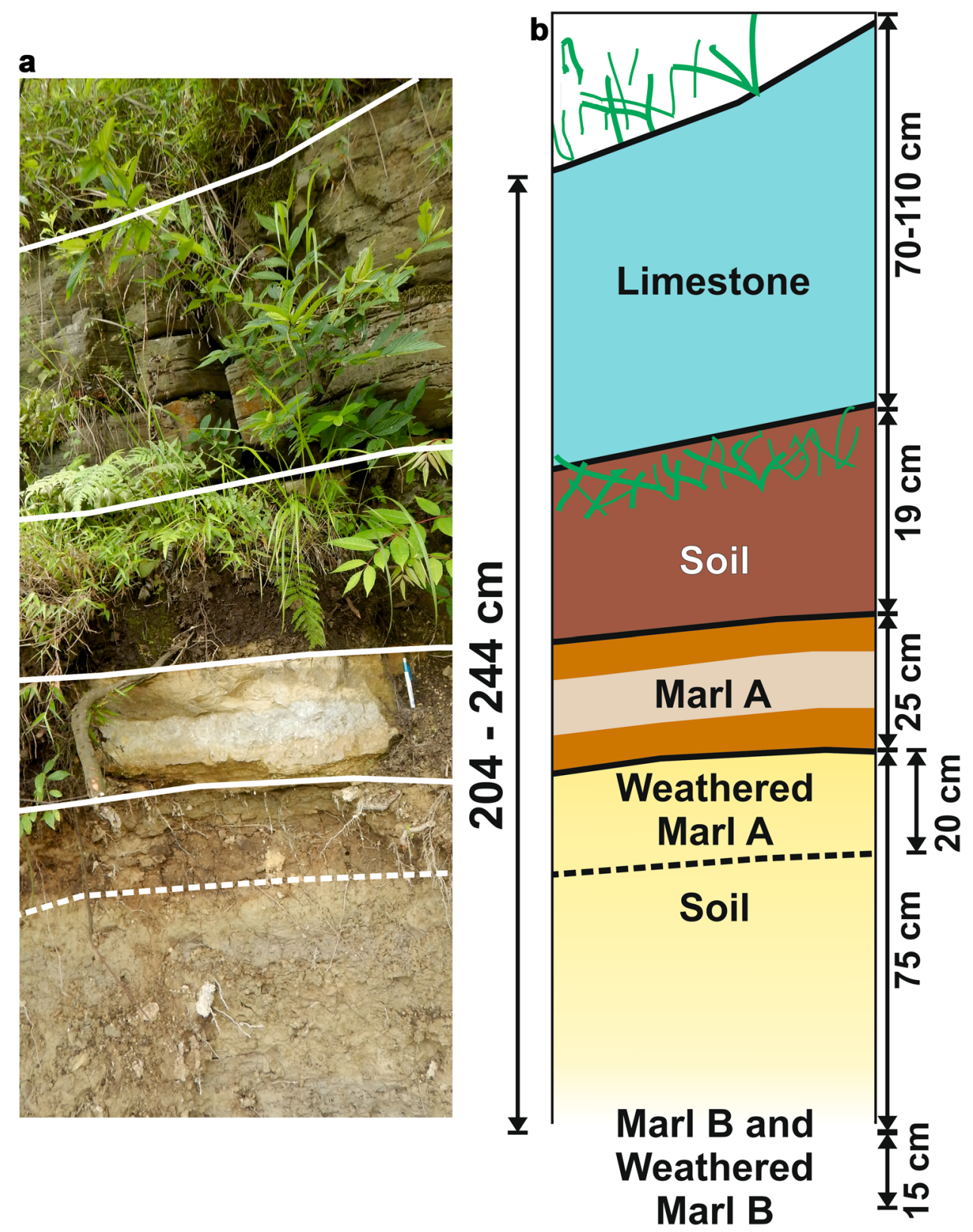

\begin{tabular}{llllll}
\hline Mineral & Limestone & Marl A & Weathered Marl A & Marl B & Weathered Marl B \\
\hline Calcite & $80.1 \pm 4.5$ & $75.2 \pm 2.0$ & $37.8 \pm 3.4$ & $67.3 \pm 4.6$ & $19.7 \pm 1.1$ \\
Dolomite & $14.2 \pm 2.6$ & 0.0 & 0.0 & 0.0 & 0.0 \\
K-Glauconite & $0.9 \pm 0.5$ & $8.0 \pm 2.2$ & $28.8 \pm 3.2$ & $13.9 \pm 3.4$ & $5.9 \pm 1.3$ \\
Fe-Glauconite & $0.2 \pm 0.2$ & $11.3 \pm 1.5$ & $6.9 \pm 1.9$ & $14.2 \pm 1.8$ & $7.6 \pm 0.9$ \\
Quartz & $2.8 \pm 1.3$ & $2.8 \pm 0.5$ & $25.4 \pm 3.0$ & $1.2 \pm 1.2$ & $10.4 \pm 2.8$ \\
Pyrite & $0.6 \pm 0.3$ & 0.0 & 0.0 & 0.0 & 0.0 \\
Sphene & $0.1 \pm 0.0$ & $1.1 \pm 0.5$ & 0.0 & 0.0 & $1.3 \pm 0.7$ \\
Apatite & 0.0 & $1.0 \pm 0.6$ & $0.8 \pm 0.8$ & 0.0 & 0.0 \\
Porosity & $1.1 \pm 0.8$ & $0.3 \pm 0.3$ & $0.1 \pm 0.1$ & $6.2 \pm 1.7$ & $19.7 \pm 1.1$ \\
\hline
\end{tabular}

Mineral abundances were determined using phase analysis on X-ray maps. Errors represent one standard error of the mean $(n=5)$ 
Table 2 Bedrock solid-state elemental compositions (vol\%)

\begin{tabular}{|c|c|c|c|c|c|c|c|c|c|c|}
\hline \multirow[t]{2}{*}{ Element } & \multicolumn{2}{|l|}{ Limestone } & \multicolumn{2}{|l|}{ Marl A } & \multicolumn{2}{|c|}{ Weathered Marl A } & \multicolumn{2}{|l|}{ Marl B } & \multicolumn{2}{|c|}{ Weathered Marl B } \\
\hline & X-ray ${ }^{\mathrm{a}}$ & ${\mathrm{ICP}-O E S^{\mathrm{b}}}$ & X-ray & ICP-OES & X-ray & ICP-OES & X-ray & ICP-OES & X-ray & ICP-OES \\
\hline $\mathrm{SiO}_{2}$ & $1.7 \pm 0.1$ & 2.0 & $14.6 \pm 1.3$ & 12.8 & $17.9 \pm 1.7$ & 23.4 & $21.4 \pm 2.1$ & 20.9 & $35.4 \pm 2.6$ & 34.2 \\
\hline $\mathrm{Al}_{2} \mathrm{O}_{3}$ & $0.4 \pm 0.1$ & 0.5 & $5.6 \pm 0.7$ & 4.4 & $6.4 \pm 0.4$ & 7.4 & $3.1 \pm 0.4$ & 7.1 & $13.5 \pm 1.4$ & 12.1 \\
\hline $\mathrm{CaO}$ & $93.7 \pm 0.2$ & 93.7 & $69.5 \pm 3.6$ & 73.2 & $68.3 \pm 2.3$ & 60.2 & $70.2 \pm 2.9$ & 64.2 & $37.8 \pm 2.1$ & 41.6 \\
\hline $\mathrm{MgO}$ & $3.1 \pm 0.3$ & 2.6 & $3.7 \pm 1.4$ & 4.2 & $1.4 \pm 0.1$ & 2.6 & $1.5 \pm 0.1$ & 2.3 & $2.9 \pm 0.2$ & 3.3 \\
\hline $\mathrm{K}_{2} \mathrm{O}$ & $0.3 \pm 0.2$ & 0.2 & $2.8 \pm 1.3$ & 1.7 & $2.6 \pm 0.1$ & 2.5 & $1.4 \pm 0.1$ & 2.5 & $5.1 \pm 1.1$ & 4.0 \\
\hline $\mathrm{TiO}_{3}$ & 0.0 & 0.0 & $0.3 \pm 0.1$ & 0.1 & $0.2 \pm 0.1$ & 0.3 & $0.3 \pm 4.4$ & 0.3 & $0.5 \pm 0.1$ & 0.5 \\
\hline $\mathrm{Fe}_{2} \mathrm{O}_{3}^{\mathrm{c}}$ & $0.5 \pm 0.1$ & 0.6 & $3.4 \pm 2.1$ & 3.3 & $3.3 \pm 0.1$ & 3.3 & $2.1 \pm 0.7$ & 2.4 & $4.9 \pm 0.9$ & 4.0 \\
\hline $\mathrm{SO}_{4}$ & $0.6 \pm 0.2$ & ND & 0.0 & ND & 0.0 & ND & 0.0 & ND & 0.0 & ND \\
\hline
\end{tabular}

Elemental abundances, expressed as oxides, were determined using X-ray maps and compared to ICP-OES data to confirm the results, both are normalized to exclude $\mathrm{CO}_{3}$

${ }^{a}$ Errors of the X-ray data represent one standard error of the mean $(n=5)$ and reflect heterogeneity of the rock

b All ICP-OES errors are identical and reported as the detection limit of the analysis as $0.01 \mathrm{wt} \%$. ND denotes not determined

c Total iron as $\mathrm{Fe}_{2} \mathrm{O}_{3}$

samples, with Marl A and B having similar concentrations (Table 2). The limestone contains small amounts of $\mathrm{Mg}$ and $\mathrm{Si}$ due to the presence of dolomite and quartz (Table 1). When weathered, the Marl A bed shows losses of all elements analyzed: $\mathrm{Ca} \quad(\tau=-0.73), \mathrm{Mg}$ $(\tau=-0.79), \quad \mathrm{Si} \quad(\tau=-0.39), \quad \mathrm{Al} \quad(\tau=-0.44), \quad \mathrm{K}$ $(\tau=-0.51)$, and $\mathrm{Fe}(\tau=-0.67)$ relative to the immobile Ti. When comparing the weathered Marl B to the unweathered Marl B using tau, most elements show little to no loss relative to $\mathrm{Ti}$ (i.e., $\mathrm{Si}=-0.02 ; \mathrm{Al}=0.02$; $\mathrm{K}=-0.04 ; \mathrm{Fe}=0.00$ ), except for $\mathrm{Ca}$ and $\mathrm{Mg}$ which show losses of -0.61 and -0.41 , respectively.

\subsection{Soil composition}

The soil profile has a mean bulk density of $1.16 \mathrm{~g} \cdot \mathrm{cm}^{-3}$, with most elements displaying partial depletion relative to the deepest sample (Fig. 2). Ca is totally depleted above $\sim 25 \mathrm{~cm}$ depth (Fig. 2a), supporting the observation from the bedrock analysis of a preferential loss of $\mathrm{Ca}$ from the system. To a lesser extent, $\mathrm{Mg}$ displays a similar trend to $\mathrm{Ca}$, with $\sim 75 \%$ loss at the soil surface (Fig. 2a). Al, K and $\mathrm{Na}$ show initial losses of $\sim 50 \%$, and $\mathrm{Fe}$ of $20 \%$, in the deepest $20 \mathrm{~cm}$, with little change in the overlying soil (Fig. $2 \mathrm{~b}-\mathrm{c}$ ). Mn is the only element in the profile that shows an increase relative to the parent material $(>100 \%)$ towards the land surface (Fig. 2d). P shows a loss ( $\sim 30 \%)$ in the deepest $20 \mathrm{~cm}$ followed by a slight increase, so that the shallow soil is only depleted relative to the deepest sample by $\sim 15 \%$ (Fig. $2 \mathrm{~d}$ ). Increases of $\mathrm{P}$ towards the surface could be due to (1) biolifting by vegetation, (2) application of phosphate fertilizer, or (3) atmospheric dust deposition. A study of dust in Jinzhong town, Guizhou Province, located $140 \mathrm{~km}$ away from Chenqi, attributed elevated $\mathrm{Mn}$ and $\mathrm{P}$ with local phosphorus mining activities (Yang et al. 2015), which may also be the source of Mn and P enrichments in our profile. Similarly, Tang et al. (2016) found that the dust in the Maolan Forest (located $241 \mathrm{~km}$ from Chenqi) was of local provenance mixed with anthropogenic sources.

\subsection{Implications for soil formation and nutrient sources}

The congruent dissolution of carbonate minerals leaves the weathered rocks comparatively enriched in silicate minerals, which are themselves relatively enriched in $\mathrm{Al}$ and $\mathrm{Si}$ due to preferential loss of $\mathrm{Ca}$ and $\mathrm{Mg}$ during incongruent dissolution. $\mathrm{Ca}$ and $\mathrm{Mg}$ are also preferentially lost during continued weathering in the soil profile. The residual silicate minerals form a structural matrix with which to support soil formation. We can use $\mathrm{Al}$, a major component of silicate minerals that is not easily leached from soils, to estimate the potential of the different bedrock lithologies to produce a $70 \mathrm{~cm}$ thick soil. Using the rock and soil bulk densities $\left(\mathrm{g} \cdot \mathrm{cm}^{-3}\right)$ plus the solid-state $\mathrm{Al}$ concentrations $\left(\mathrm{g} \cdot \mathrm{g}^{-1}\right.$; Table 2), we calculated the mass of $\mathrm{Al}$ per unit volume as $0.01,0.16,0.08$ and $0.15 \mathrm{~g} \mathrm{~cm}^{-3}$ in the limestone, Marl A, Marl B and soil, respectively. Therefore, to produce $70 \mathrm{~cm}^{3}$ of soil from the dominant limestone bedrock, which contains only $\sim 4 \mathrm{vol} \%$ silicate minerals, $967 \mathrm{~cm}^{3}$ of limestone would have to be weathered, with no erosive loss. To produce a $70 \mathrm{~cm}^{3}$ soil from the Marl A and Marl B bedrock, would require weathering of 65 or 


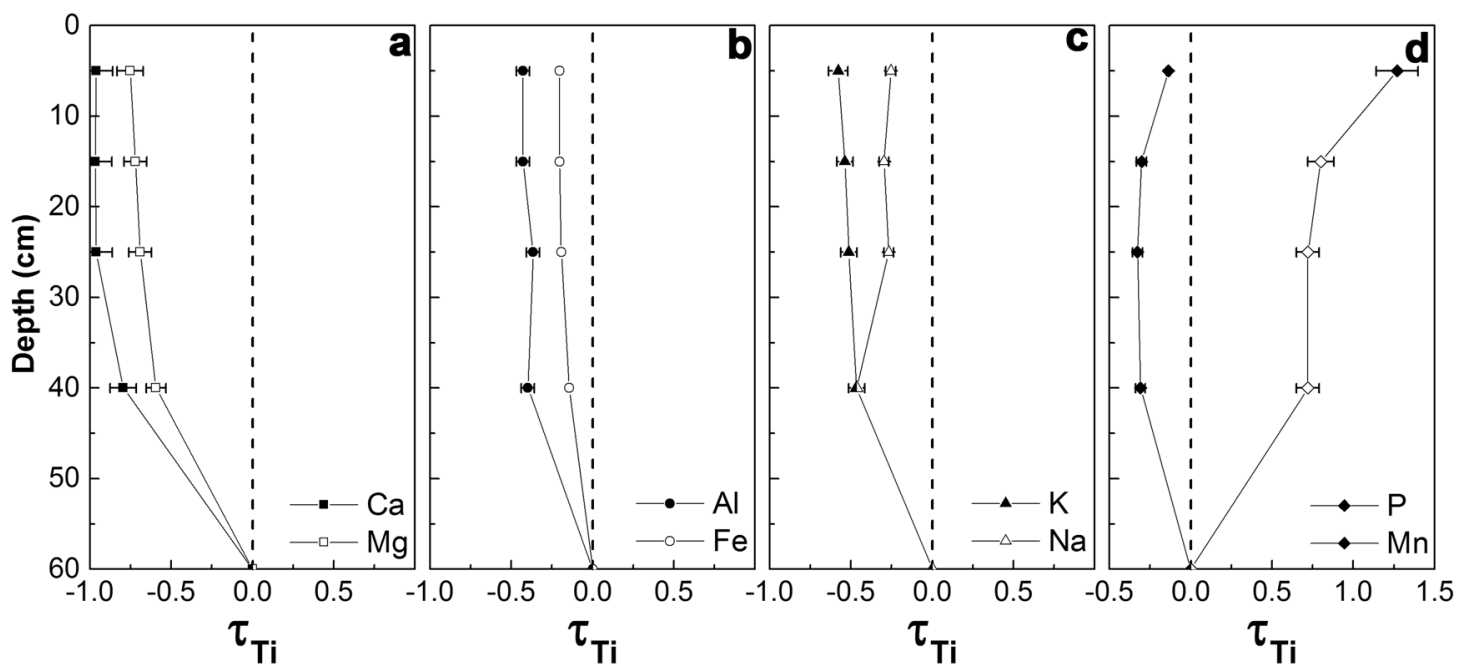

Fig. 2 Mass transfer coefficients $\left(\tau_{\mathrm{Ti}}\right)$ in the soil weathering profile for major elements, calculated with Ti as the immobile element with the deepest sample used as the parent material (Eq. 1): a Ca and $\mathrm{Mg}$; b $\mathrm{Al}$ and $\mathrm{Fe} ; \mathbf{c} \mathrm{K}$ and $\mathrm{Na}$; $\mathbf{d} \mathrm{P}$ and $\mathrm{Mn}$. The dotted line at $\tau_{\mathrm{Ti}}=0$ indicates no mass loss or gain relative to the parent material for a given element. Samples were taken from the following depths: 0-10, 10-20, 20-30, 30-50 and 50-70 cm with the data plotted at the midpoint of each $10 \mathrm{~cm}$ interval. Solid-state concentrations used in Eq. 1 were determined using ICPOES. Analytical uncertainty for all elements $\leq 5 \%$, with this maximum conservatively used to propagate error through Eq. 1

$130 \mathrm{~cm}^{3}$, respectively, again with no erosive loss. Exposed rock in Puding County is $\sim 79 \%$ carbonate (Wang et al. 2014); assuming that the marls analysed here are representative of the remaining $\sim 21 \%$, it is clear that although significantly less abundant than limestone in the catchment, the marl beds are disproportionately important in terms of soil formation. Similarly, natural sources of the nutrient elements in the profile, with the exception of $\mathrm{Ca}$, must derive from weathering of the marl bedrock or dust input. The depletion profiles presented here (Fig. 2) are consistent with in situ soil formation from bedrock, although transport and deposition of soil and weathering products in other parts of the catchment are likely.

\section{Conclusions}

Both $\mathrm{Ca}$ and $\mathrm{Mg}$ are preferentially lost during weathering of all rock types and in the soil profile, leaving both the weathered rocks and soils relatively enriched in non-carbonate (silicate and oxide) minerals. Similarly, the low nutrient content of carbonate rock, which is due to the scarcity of non-carbonate minerals, means that the spatial variation in ecosystem productivity and environmental resilience may be strongly controlled by the distribution of relatively silicate-rich rocks. Although the limestone bedrock contains some of these minerals, they are likely insufficient to support significant soil formation and nutrient production. Therefore, the marl layers in the catchment represent an integral and critical part of the local karst ecosystem.
Acknowledgements The authors thank Stuart Kearns (University of Bristol) for laboratory assistance and Tim Barrows (University of Exeter) for field assistance. This work was supported by the National Environmental Research Council of the UK (Grant Nos. NE/N007530/1 and NE/N007603/1) and the National Science Foundation of China (Grant No. 41571130042).

\section{Compliance with ethical standards}

Conflict of interest On behalf of all authors, the corresponding author states that there is no conflict of interest.

Open Access This article is distributed under the terms of the Creative Commons Attribution 4.0 International License (http://creative commons.org/licenses/by/4.0/), which permits unrestricted use, distribution, and reproduction in any medium, provided you give appropriate credit to the original author(s) and the source, provide a link to the Creative Commons license, and indicate if changes were made.

\section{References}

Anderson SP, Dietrich WE, Brimhall GH (2002) Weathering profiles, mass-balance analysis, and rates of solute loss: linkages between weathering and erosion in a small, steep catchment. Geol Soc Am Bull 114:1143-1158

Chen R, Bi K (2011) Correlation of karst agricultural geo-environment with non-karst agricultural geo-environment with respect to nutritive elements in Guizhou. Chin J Geochem 30:563-568

Chinese Academy of Sciences, Insitute of Karst Geology Research Group (1979) China karst studies. Geological Publishing House, Beijing (in Chinese)

Deer WA, Howie RA, Zussman J (2013) An introduction to the rockforming minerals. In: Mineralogical Society, 3rd edn. London $498 \mathrm{p}$

Huang QH, Cai YL (2007) Spatial pattern of karst rock desertification in the middle of Guizhou Province, Southwestern China. Environ Geol 52:1325-1330 
Tang Y, Han G, Li F, Wu Q (2016) Natural and anthropogenic sources of atmospheric dust at a remote forest area in Guizhou karst region, Southwest China. Geochem: Explor Environ, Anal $16: 159-163$

Wang SJ (2003) The most serious eco-geologically environmental problem in Southwestern China karst rocky desertification. Bull Mineral Petrol Geochem 22:120-126

Wang J, Zou B, Liu Y, Tang Y, Zhang X, Yang P (2014) Erosioncreep-collapse mechanism of underground soil loss for the karst rocky desertification in Chenqi village, Puding County, Guizhou, China. Environ Earth Sci 72:2751-2764
White AF, Blum AE, Schulz MS, Vivit DV, Stonestrom DA, Larsen M, Murphy SF, Eberl D (1998) Chemical weathering in a tropical watershed, Luquillo Mountains, Puerto Rico: I. Longterm versus short-term weathering fluxes. Geochim Cosmochim Acta 62:209-226

Yang Q, Chen H, Li B (2015) Source identification and health risk assessment of metals in indoor dust in the vicinity of phosphorus mining, Guizhou Province, China. Arch Environ Contam Toxicol 68:20-30 